Editorial

\title{
Introduction: Rethinking Safety of Journalists
}

\author{
Kristin Skare Orgeret ${ }^{1, *}$ and William Tayeebwa ${ }^{2}$ \\ ${ }^{1}$ Department of Journalism and Media Studies, Oslo Metropolitan University, 0130 Oslo, Norway; \\ E-Mail: kristo@oslomet.no \\ ${ }^{2}$ Department of Journalism and Communication, Makerere University, Kampala, Uganda; E-Mail: william@chuss.mak.ac.ug \\ * Corresponding author
}

Submitted: 5 February 2020 | Published: 25 February 2020

\begin{abstract}
The introductory chapter to the thematic issue, entitled "Rethinking Safety of Journalists," shows how promoting the safety of journalists is closely related to press freedom. It presents the articles of the thematic issue and highlights how the safety of journalists is no longer a concern of individuals or individual nation states only, but is now also a global concern, whereby the international community is obliged to come to the defense of journalists' safety.
\end{abstract}

\section{Keywords}

gender; journalism; press freedom; safety of journalists; threats

\section{Issue}

This editorial is part of the issue "Rethinking Safety of Journalists" edited by Kristin Skare Orgeret (Oslo Metropolitan University, Norway) and William Tayeebwa (University of Makerere, Uganda).

(C) 2020 by the authors; licensee Cogitatio (Lisbon, Portugal). This article is licensed under a Creative Commons Attribution 4.0 International License (CC BY).

Journalists throughout the world are increasingly faced with attacks on their life, their dignity, and the integrity of their work. Whereas only two correspondents were killed during the entire period of World War I, the situation is radically different a bit more than a hundred years later. On average, every five days a journalist is killed for bringing information to the public and there is an increasing tendency that journalists themselves are the aim of violence. The threats range from harassment to arbitrary detention, kidnapping, physical attacks, and in the most extreme cases, killing. This happens against a backdrop of a rising anti-media rhetoric and the discrediting of newsworthy and accurate journalistic reportage as "fake news" (Ireton \& Posetti, 2018). Furthermore, the worrying gender dimensions of safety and tactics for censoring and silencing journalists add to the current state of affairs. Threats to journalists occur both online and offline and women journalists are particularly affected by gender-specific forms of attacks, such as sexual harassment and violence. Promoting the safety of journalists is closely related to press freedom as the following quote by the Deputy Director-General of UNESCO reminds us:
Safety for journalists is a matter of public concern that is wide-ranging. It is vital for those who practice journalism, for their families and for their sources. It is essential for the wellbeing of media institutions, civil society, academia and the private sector more broadly. If we value the free flow of information for citizens, their governments and their international organisations, then the safety of journalists is central. (Henrichsen, Betz, \& Lisosky, 2015)

This thematic issue of Media and Communication presents fresh research on the current situation of safety of journalists from various regions and countries, as well as reflections on how democratic developments may be safeguarded by finding ways to protect journalists and freedom of speech. The articles presented here both point at some of the most crucial challenges and to ways of addressing them. In doing so, they highlight how the safety of journalists is no longer a concern of individuals or individual nation states only, but is now also a global concern, whereby the international community is obliged to come to the defense of journalists' safety, thus 
warranting evoking the global 'responsibility to protect' (R2P) journalists. As Simon Cottle emphasizes, the protection of journalists "is a matter for all of us as it reaches deep inside the conduct of human affairs in global society" (Cottle, 2017, p. 29).

The last years have also seen an increased awareness and a growth of initiatives and coalitions to push back the threats against journalists. Whereas scholarly works within the field of safety of journalists were rare only a few years ago, we now witness an explosive interest in conventions such as the academic conference on the safety of journalists as part of the UNESCO's World Press Freedom Day's Global Conference, and in the annual conference on safety of journalists at Oslo Metropolitan University. All the articles here were first presented in one of these conferences, both results of transnational academic coalitions.

This thematic issue, entitled "Rethinking Safety of Journalists," encompasses research into how matters of safety influence epistemological news production processes. More specifically, it explores what knowledge journalists have when it comes to different matters of safety.

The three first articles are from Africa, Europe, and Asia respectively. Although the contexts are different, all three articles explore what knowledge journalists have when it comes to different aspects of safety and find some similar traits in how they respond to vulnerable situations. In doing so, all three clearly illustrate that if journalists' access to information is restricted, then the entire society suffers since it is deprived of getting the information needed to make informed decisions. In their article, Gerald Walulya and Goretti L. Nassanga (2020) discuss the increasingly difficult situation of journalists covering political elections in many less democratic societies. Their findings show that Ugandan journalists face more safety and security risks during elections. Some of the key challenges include state harassment, arrest of those considered critical to the state and denial of access to important information. Based on in-depth interviews, the article shows how due to concerns of their own safety, journalists respond to the insecure work environment by engaging in self-censorship, thereby giving biased or limited information to the public. The article identifies gaps that media development agencies can help to close if the media are to play their rightful role in a democratic society especially during electoral processes.

Self-censorship as a strategy of self-protection is also the concern of Sofia lordanidou, Emmanouil Takas, Leonidas Vatikiotis, and Pedro García's (2020) contribution. Taking the South European situation after the economic crisis as their starting point, the authors show how Greece, Cyprus, and Spain came under a surveillance regime where everything concerning public spending, labour market, and social policy came under a rigorous monitoring of European institutions. A new working environment emerged where many of the experienced and highly-paid professionals were replaced by younger journalists. Through qualitative interviews, the article explores how to what extent the logic of memoranda affected the journalistic practice in the three countries. It shows how journalists operated in a conflictual situation in the forefront of pressures, not only having to manage an extended, stressful and unpleasant situation, but also having to analyze it, sometimes even serve it.

In their article, Mubashar Hasan and Mushfique Wadud (2020) argue that the parameters for evaluating the safety of journalists in an authoritarian state go beyond the conventional, global knowledge of what is known about the safety of journalists. Against a backdrop of increasing surveillance, attacks on journalist by force and legal means in a political climate that is not democratic, the article investigates how Bangladeshi journalists define safety. Based on in-depth interviews with Bangladeshi journalists, the authors explore how the concept of journalists' safety has three intertwined dimensions: First, journalists' safety incorporates avoiding bodily harm; second, in order to remain safe, journalists undertake various tactics including compromising the objectivity of news in a regime where security apparatus and pro-government journalists work in tandem to surveil and intimidate non-partisan journalists; third, such journalists' safety model decreases public faith in media, as media no longer can be said to play the role of a watchdog.

Although studies in the last few years show that being a local journalist in a conflict area is the most dangerous position, the role of local fixers is still under-researched. This is the topic of Kiyya Baloch and Kenneth Andresen's (2020) article. As a backbone of reporting in war and conflicts, fixers are an essential component to the foreign correspondent in conflict zones. Based on data from interviews with local fixers and journalists in Pakistan, the article exposes the many security problems for local fixers. It also shows that the fixers' rights and interests are not guarded by media organizations or the government. Fixers increasingly face censorship by the security agencies and death threats from the militants. The physical threats to journalists in general and to fixers working in militancy-hit areas of Pakistan have increased over the years, and a number of fixers have lost their lives chasing stories for the western media. This study discusses the harsh realities fixers face in the conflict zones of Pakistan where international press lack access due to increasing restrictions imposed by the government, and violence perpetrated against media workers by Islamic State, Taliban, and Baloch separatists.

Samiksha Koirala's (2020) article "Female Journalists' Experience of Online Harassment: A Case Study of Nepal" examines the experiences of women journalists in Nepal in the context of a rapidly growing expansion of the internet. By examining the findings of qualitative in-depth interviews, the article argues that online platforms are threatening press freedom in Nepal, mainly by silencing women journalists. The study also indicates that the problem is particularly severe in a patriarchal society 
such as Nepal, as a significant number of incidents of abuse go unreported, largely because of the culture of shame and ineffective legislation. The findings show that some of the women journalists experiencing harassment tolerate the harassment by being "strong like a man," while many of them stay away from social media platforms to avoid the abuse. The article suggests that individual efforts to tackle the vicious issue like misogyny might not be enough; and collective efforts from legislation of media organisations to empowerment of feminist movements are required to address the issue.

The need to elevate individual attacks to a structural level is also the concern of the next article. Trond Idås, Kristin Skare Orgeret, and Klas Backholm (2020) discuss sexual harassment among Norwegian journalists as a dimension of safety of journalists in the times of the global \#MeToo movement. Through a study focusing on sexual harassment among media workers, the article investigates the extent and types of sexual harassment experienced by the editorial staff in Norwegian newsrooms, and what effect such kind of experiences might have on their professional life. The article discusses sexual harassment through three interrelated questions: What is the extent of sexual harassment against journalists? What may coping strategies be? And from the perspective of safety of journalists-how can the newsrooms be better prepared to fight sexual harassment? The results show that female, young, and temporary media workers are significantly more targeted than others. The findings feed into a discussion of what strategies media houses can use in order to be better prepared in the fight against sexual harassment.

One way to prepare journalists themselves to face the increased dangers of the profession is through safety training courses designed to provide journalists with guidance to assess risk and mitigate them. In the article "Reconsidering Journalists' Safety Training," Marte Høiby and Mariateresa Garrido V. (2020) ask whether content of such training and guidance is informed by actual threats and risks relevant for journalists working in the field. Through an evaluation of five safety training documents, they identify various aspects of safety addressed in training offered to locally and internationally deployed journalists. They find that the trainings and manuals to some extent address specific variations in context, but that detailed attention towards gender differences in risk and other personal characteristics are not given equivalent weight. They recommend that addressing journalistic practice and personal resources is fundamental to all journalist safety training since it is at the personal, practical, and media organisational levels that the mitigation encourage by these trainings can happenedd.

The two last articles of the thematic issue discuss the way forward for monitoring the safety of journalists globally as a means to prevent attacks on the communicative functions of journalism. In his article, Guy Berger (2020) highlights the potential for increased and more standardised monitoring of the safety of journalists in the light of the specific indicator that has been agreed by the UN as part of the Sustainable Development Goals (SDGs). The indicator concerned treats the safety of journalists as a benchmark for tracking progress on SDG target 16.10, which specifies "public access to information and fundamental freedoms" as a development aspiration. The article argues that inclusion of this indicator in the SDGs provides a universally legitimated framework with strong catalytic potential and that this holds a promise of improved, more comparative, and increased research output. The results of new research stimulated by this development, particularly at country level, could have real impact on the safety of journalists.

The very last article by Jackie Harrison, Diana Maynard, and Sara Torsner (2020) also highlights the SDG indicator 16.10 .1 as an important monitoring agenda for the global recording of violations against journalists. The article argues that the need for extensive collection of data on violations against journalists also raises a number of methodological challenges: the lack of conceptual consistency; the lack of methodological transparency; the need for sophisticated data categorization and disaggregation to enable data to be merged from different sources; the need to establish links to understand causal and temporal relations between people and events; and the need to explore and utilize previously untapped data sources. Suggesting a way forward to further strengthen the monitoring of SDG 16.10.1, the article proposes to develop a robust and reliable events-based methodology and a set of tools which can facilitate the monitoring of the full range of proposed 16.10 .1 categories of violations, reconcile data from multiple sources in order to adhere to the established category definitions, and to further disaggregate the proposed 16.10.1 categories to provide more in-depth information on each instance of a violation. This, they argue, will ultimately contribute towards better understanding of the contextual circumstances and processes producing aggressions against journalists.

\section{Acknowledgments}

The authors would like to express their thanks to NORAD for their financial support through the Norhed project Bridging Gaps (QZA-0487 UGA) of this thematic issue.

\section{Conflict of Interests}

The authors declare no conflict of interests.

\section{References}

Baloch, K., \& Andresen, K. (2020). Reporting in conflict zones in Pakistan: Risks and challenges for fixers. Media and Communication, 8(1), 37-46.

Berger, G. (2020). New opportunities in monitoring safety of journalists through the UN's 2030 sustainable development agenda. Media and Communica- 
tion, 8(1), 78-88.

Cottle, S. (2017). Journalist killings and the responsibility to report. In U. Carlsson \& R. Pöyhtäri (Eds.), The assault on journalism: Building knowledge to protect freedom of expression (pp. 129-141). Gothenberg: Nordicom.

Harrison, J., Maynard, D., \& Torsner, S. (2020). Strengthening the monitoring of violations against journalists through an events-based methodology. Media and Communication, 8(1), 89-100.

Hasan, M., \& Wadud, M. (2020). Re-conceptualizing safety of journalists in Bangladesh. Media and Communication, 8(1), 27-36.

Henrichsen, J. R., Betz, M., \& Lisosky, J. M. (Eds.). (2015). Building digital safety for journalism. Paris: United Nations Educational, Scientific and Cultural Organization.

Høiby, M., \& Garrido V., M. (2020). Reconsidering journalist safety training. Media and Communication, 8(1), 68-77.

Idås, T., Skare Orgeret, K., \& Backholm, K. (2020).
\#MeToo, sexual harassment and coping strategies in Norwegian newsrooms. Media and Communication, 8(1), 57-67.

Iordanidou, S., Takas, E., Vatikiotis, L., \& García, P. (2020). Constructing silence: Processes of journalistic (self-)censorship during memoranda in Greece, Cyprus, and Spain. Media and Communication, 8(1), 15-26.

Ireton, C., \& Posetti, J. (Eds.). (2018). Journalism, 'fake news' and disinformation: A handbook for journalism education and training. Paris: UNESCO. Retrieved from https://en.unesco.org/sites/default/ files/journalism_fake_news_disinformation_print_ friendly_0.pdf

Koirala, S. (2020). Female journalists' experience of online harassment: A case study of Nepal. Media and Communication, 8(1), 47-56.

Walulya, G., \& Nassanga, G. L. (2020). Democracy at stake: Self-censorship as a self-defence strategy for journalists. Media and Communication, 8(1), 5-14.

\section{About the Authors}
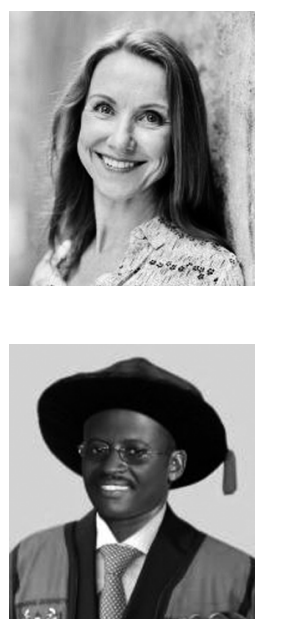

Kristin Skare Orgeret (Dr.Art) is Professor in Journalism and Media Studies at Oslo Metropolitan University, Norway. She has published extensively within the field of journalism in conflict situations, safety of journalists, global journalism, and media and gender. She has worked as a researcher and lecturer in several countries in Africa and Asia and is currently coordinating the Norhed project 'Bridging Gaps' - a cooperation between journalism schools in Uganda, Nepal, Norway, and South Sudan together with William Tayeebwa.

William Tayeebwa (PhD) is a Senior Lecturer and Head of the Department of Journalism and Communication at Makerere University, Uganda. Tayeebwa holds a Doctorate of Philosophy in Communication from Concordia University, Montreal, Canada, and has published several articles and academic chapters within the field of Peace Journalism and conflict studies. He is the coordinator of the Norhed Project UGA. 